\title{
Cognitive Processes in Adolescents with Borderline Personality Traits and Its Relation to Temperament and Comorbid Psychopathology
}

\author{
Megha Rathi ${ }^{1}$, Chhavi Tewary ${ }^{2}$, Prathama G Chaudhuri ${ }^{3}$
}

\begin{abstract}
Aims: This study aims to assess the differences and relationship between temperament, character, cognitive errors, coping strategies, and psychopathology in adolescents with and without borderline personality traits.

Materials and method: One hundred adolescents from urban upper-middle-class families were included in this cross-sectional, randomized comparative study. The clinical population was selected from a multispecialty mental health clinic, whereas the control group was taken from the community through matching techniques. Millon Adolescent Clinical Inventory (MACI), Temperament and Character Inventory (TCI), Cognitive Error Questionnaire, and Coping Strategies Inventory were administered. Mann-Whitney U test was done along with Spearman's rank difference correlation.

Result: The clinical group had high novelty seeking, harm avoidance, and low persistence. In terms of expressed concerns and psychopathology, the clinical group has high identity diffusion, family discord, childhood abuse, anxious affect impulsivity, and depression. Furthermore, it has a higher use of cognitive errors along with maladaptive coping strategies. There is a negative correlation between cognitive errors and maladaptive coping along with persistence and suicidal tendency.

Conclusion: Clinical groups have temperament difficulties, more psychopathology, and higher usage of cognitive error and maladaptive coping strategies.

Clinical significance: The current study aims to assess the psychological factors contributing to the development of borderline personality organization, which would facilitate early and effective psychological intervention. Recognition of risk factors would lead to diagnosis at the early stage of symptoms, improving prognosis.

Keywords: Character, Cognitive errors, Comorbid psychopathology, Coping strategies, Emerging borderline personality, Expressed concerns, Temperament.

Indian Journal of Private Psychiatry (2020): 10.5005/jp-journals-10067-0050
\end{abstract}

\section{INTRODUCTION}

Borderline personality disorder (BPD) is a serious form of psychopathology characterized by an interaction of social, cognitive, emotional, and behavioral dysregulation. The disorder is characterized by mood swings, impulsivity, interpersonal relationship difficulty, fear of abandonment, and self-harming behavior, and its onset is usually before the age of 18 years. Borderline personality has its root in childhood and adolescence. The causal factors for BPD have been linked to developmental pathways that begin in childhood. ${ }^{1}$ Childhood abuse and neglect along with maladaptive parenting during childhood are considered to be important etiological factors in the development of borderline personality traits. ${ }^{2}$ This emotional and physical abuse may contribute to a disturbance in emotional regulation, ${ }^{3}$ and transmission of social knowledge ${ }^{4}$ which results in a deficit in the psychological process of emotional regulation and social cognition. ${ }^{5}$ Furthermore, childhood maltreatment leads to increased stress and lower self-efficacy in adolescents with borderline personality traits. ${ }^{6}$ Thus, the study attempts to evaluate the presence of cognitive errors and coping strategies in adolescents with borderline personality traits. While the importance of cognitive errors in assessing the world in general, and relationships in particular, is well documented, ${ }^{7}$ lesser insight is available on how they interfere with the development of personality psychopathology by possibly leading to inaccurate judgments and illogical interpretations of
${ }^{1}$ Department of Applied Psychology, Calcutta University, Clinical Wing, Caring Minds, Kolkata, West Bengal, India

${ }^{2}$ Department of Clinical Psychology, Institute of Psychiatry, Kolkata, West Bengal, India

${ }^{3}$ Department of Psychiatry, Calcutta National Medical College, Kolkata, West Bengal, India

Corresponding Author: Prathama G Chaudhuri, Department of Psychiatry, Calcutta National Medical College, Kolkata, West Bengal, India, Phone: +91 9831251629, e-mail: chaudhurip@yahoo.com

How to cite this article: Rathi M, Tewary C, Chaudhuri PG. Cognitive Processes in Adolescents with Borderline Personality Traits and Its Relation to Temperament and Comorbid Psychopathology. Ind J Priv Psychiatry 2020;14(1):20-25.

Source of support: Nil

Conflict of interest: None

external behavior. Furthermore, an individual's way of responding to cognitive errors may also be influenced by coping strategies in response to stress. Coping strategies are internally motivated ways of responding to internal and external stressors and encompass affective, cognitive, and behavioral components. ${ }^{8}$ Research has shown that maladaptive coping strategies can result in a feeling of distress. ${ }^{9}$ Coping strategies refer to specific efforts, both behavioral and psychological that people employ to master, tolerate, reduce, 
or minimize stressful events. ${ }^{10}$ Consequently, young people with a BPD may experience emotional lability and impulsivity along with minimization or dismissal of their difficulties in the interpersonal sphere, who attribute their problems to the typical stresses and strains of the adolescent transition. This may preclude access to appropriate help for their difficulties.

The study also purports to examine the temperament and character traits in adolescents with borderline personality traits. Temperament refers to the automatic emotional responses to experience, whereas, character refers to self-concepts and individual differences in goals, values, intentions, and the meaning and salience of experiences in life. Given the developmental continuities between childhood temperament and personality, temperament is an important etiological and psychological factor to be considered for the formation of personality disorder symptoms in adolescence. ${ }^{11}$ Childhood temperament reflects early individual differences in reactivity and self-regulation, ${ }^{12}$ which are core features of borderline personality traits. Thus, childhood temperament and emerging personality traits may be a manifestation of the same basic underlying dimension. ${ }^{13}$ Thus, temperamental and characterological traits were considered for evaluation in the current study.

Research studies suggest that there is a steady increase in the incidence of BPD in 14- to 17-year-old girls between 2000 and 2012. ${ }^{14}$ As per the National Mental Health Survey of India (2015-2016), the prevalence of psychiatric disorders among adolescents (13-17 years) is around $7.3 \% .{ }^{15}$ Personality disorder traits emerge in approximately $20 \%$ of the adolescent population. ${ }^{16}$ Furthermore, studies show the prevalence of borderline personality traits in $11 \%$ of outpatient adolescents, ${ }^{17}$ between 19 and 53\% in hospitalized adolescents, ${ }^{18} 62 \%$ in hospitalized suicidal adolescents, ${ }^{19}$ and $78 \%$ in adolescents attending the emergency department for self-harm behavior. ${ }^{20}$ Emerging personality disorder is seemingly increasing in the population, which is a challenging issue for all mental health professionals due to its high lifetime rates of self-harming behaviors. Thus, if not identified and treated early, the prognosis lowers. Early adolescence is a period during which borderline personality traits manifest in terms of a complex clinical picture. With early diagnosis and treatment, symptoms may be controlled and normalized. From the above facts, it can be delineated that there are manifold risk factors associated with the development of BPD, some of which are explored in the present study.

The present study aims to explore the effect of cognitive errors and coping strategies in adolescents with emerging borderline personality traits along with its relationship with clinical syndromes and temperamental characteristics.

\section{Methods}

It is a cross-sectional study with two randomized group designs.

\section{Participants}

One hundred adolescents from Kolkata belonging to the age group of 13 to 17 years were selected through a purposive sampling strategy to participate in the study. The study comprised of two groups, adolescents with emerging borderline personality traits and those without emerging borderline personality traits, with 50 in each group. In both groups, we had 12 males and 38 females. Participants of the matched control group ( $\mathrm{N}-50)$ were taken from the community keeping in mind the sociodemographic profile of the clinical group. The presence of psychopathology was ruled out using Millon Adolescent Clinical Inventory (MACI). Participants having elevation in any scale of $\mathrm{MACl}$ were excluded from the study. For clinical groups, individuals having a base rate (BR) score above 75 on the borderline tendency scale were selected from a multispecialty mental health institution in Kolkata. Participants with any chronic physical illness and those having a history of mental illness were excluded. Participants with a known history of any substance use were excluded from the study. All the participants were included in the study after obtaining consent from them. The groups were matched on the basis of age, education, religion, socioeconomic status, and area of residence. All the participants belonged to middle or upper socioeconomic status according to Kuppuswamy socioeconomic status scale and were fluent in English, having a minimum of grade VIII level of education. The study was conducted from April 2019 to December 2019.

\section{Assessments}

An information schedule was prepared to elicit sociodemographic profiles along with current chief complaints of the client and a brief history of their psychiatric illness was prepared for the study. Informed consent was obtained using the standard informed consent form laid down by the Indian Council of Medical Research (ICMR, 2017), the apex body governing biomedical research in India.

- $\mathrm{MACl}^{21}$ is a self-report inventory designed to assess personality styles and levels of psychopathology amongst adolescents in clinical settings. MACl consists of 160 true/false items generating 31 clinical scales, including 12 scales reflecting the basic personality pattern consistent with Millon's theory of personality (personality patterns), 8 scales reflecting the primary concerns of adolescents (expressed concerns), and 7 scales reflecting clinical syndromes. $\mathrm{MACl}$ has a high internal consistency reliability of 0.73 and the validity coefficient was 0.82 .

- $\mathrm{TCl}$ developed by Cloninger, ${ }^{22}$ is a quantitative rating of seven dimensions of personality. It evaluates four major temperament dimensions (harm avoidance, novelty seeking, reward dependence, and persistence) and three major character dimensions (self-directedness, cooperativeness, and self-transcendence). Each of these higher-order temperament and character dimensions is composed of certain components or subscales. The self-report version of the TCI has 240 items with a forced binary answer of true or false. The administration of the scale takes about 30 to 45 minutes. The $\mathrm{TCl}$ comprises four temperament scales and three character scales. The temperament scales are called novelty seeking (NS), harm avoidance $(\mathrm{HA})$, reward dependence $(\mathrm{RD})$, and persistence $(\mathrm{PE})$. The character scales are self-directedness (SD), cooperativeness (CO), and self-transcendence (ST).

- Cognitive error questionnaire ${ }^{23}$ is a 24 -item self-report cognitive error questionnaire to measure the types of cognitive distortions that Aaron Beck theorized to lead to depression. This tool assesses four types of distortions: catastrophizing, overgeneralizing, personalizing, and selective abstraction. Lefebvre reported that the general scale had internal consistency in the range of 0.89 to 0.92 .

- Coping strategies inventory ${ }^{24}$ is a 72 -item questionnaire designed to assess coping thoughts and behaviors in response to a specific stressor. There is a total of 14 subscales on the CSI including 8 primary scales (problem-solving, cognitive restructuring, social support, expressed emotions, problem avoidance, wishful thinking and social withdrawal), four secondary subscales (problem focused engagement, emotion 
focused engagement, problem focused disengagement and emotion focused disengagement), and two tertiary subscales (engagement and disengagement). Cronbach's alpha reported a coefficient of reliability for measures of the coping process. The alpha coefficients for the CSI range from 0.71 to 0.94 . Validity for CSI has been assessed using factor structure, criterion validity, and construct validity. All these indicate the high validity of the scale. In the current study, only eight primary scales were assessed. Items were scored from 0 to 4.

- Kuppuswamy's socioeconomic status scale was devised by Kuppuswamy in 1976. It is a composite score of education and occupation of the head of the family, which yields a score of 3 to 29. The scale classifies the study population into high, middle, and low socioeconomic status. ${ }^{25}$

\section{Procedure}

All consecutive patients who reported with a complaint of borderline personality traits to our clinic and fulfilled the inclusion and exclusion criteria were included in our study, until 50 female patients were recruited. The prospective clinical patients for the study were contacted with the help of the outpatient department of a multispecialty mental health clinic in Kolkata in Eastern India. The nonclinical control group participants were contacted from within the community. All participants were screened through clinical interview and assessment tools after taking informed consent. Along with the information schedule, all the scales were administered to the participants individually. The data collected were then scored and tabulated for further statistical treatment and determining the objectives.

\section{Statistical Analysis}

The data were statistically analyzed. Mann-Whitney U test was done to see if there is any significant difference in variables between the clinical and control group. Spearman rank difference correlation was computed to assess the relationship of temperament and character to clinical syndromes. All the findings were interpreted at a $95 \%$ confidence interval.

\section{Results}

In terms of sociodemographic variables, the mean age of the adolescents in the clinical group is $15.8 \pm 1.12$ years and for the control group mean age is $16.2 \pm 1.8$ years. Furthermore, the mean education for the clinical group is $13.0+0.86$ years, whereas for the control group, it is $13.2+1.03$ years.

Spearman correlation was done for the clinical group to determine the relationship between cognitive errors and coping strategies. Results suggested that catastrophizing is significantly negatively correlated with cognitive restructuring $(\mathrm{rs}(98)=-0.653$, $p=0.041)$ and expressed emotions ( $\mathrm{rs}(98)=-0.752, p=0.018)$.

Furthermore, correlation was computed to ascertain the relationship between clinical syndromes, temperament and character for the clinical group. Results indicate significantly negative correlation between persistence and suicidal tendency $(\mathrm{rs}(98)=-0.705, p=0.023)$.

\section{Discussion}

We have conducted a cross-sectional study to determine the differences in expressed concerns, coping strategies, cognitive errors, clinical syndromes, temperaments, and characters in adolescents with and without borderline personality traits.
Table 1 shows identity diffusion to be significantly higher in the clinical group. Identity disturbance is manifested by uncertainty about several issues relating to identity, such as self-image, gender identity, long-term goals or career choice, friendship patterns, values, and loyalties, such as "Who am I?", "I feel like I am my sister when I am good." According to Kernberg, identity diffusion is a core element in borderline personality organization. Individuals with borderline personality traits tend to struggle with a profound lack of sense of self and are unsure about their identity. Peer insecurity and family discord are high in the clinical group. ${ }^{26}$ According to Bowlby, adolescents with borderline personality traits tend to have impairment in attachment styles leading to the formation of disorganized or insecure attachment styles. A secure attachment should engender a positive, coherent, and consistent self-image and a sense of being worthy of love, combined with a positive expectation that significant others will be generally accepting and responsive. ${ }^{27}$ This portrait of secure attachment contrasts dramatically with the malevolent or split representations of self and others, as well as with the needy, manipulative, and angry relationships that characterize persons with BPD. ${ }^{28}$

Childhood abuse, which is significantly high for the clinical group, refers to any behavior by parents, caregivers, or other adults that is outside the norms of conduct and entails a substantial risk of causing emotional harm, which may be reflected through the disorder of personality. ${ }^{29}$ A study by Widom et al., who studied 500 children with a history of physical and sexual abuse and neglect, found that significantly more abused and neglected children met the criteria for BPD in adulthood as compared to subjects with no history of abuse or neglect. ${ }^{30}$ Childhood abuse is said to be an important factor in the early years of life, leading to trauma and affective instability. ${ }^{31}$

Table 1: Comparison between clinical and control groups in terms of expressed concern scales

\begin{tabular}{|c|c|c|c|c|c|}
\hline Variables & Group & $\begin{array}{l}\text { Mean } \\
\text { rank }\end{array}$ & $\begin{array}{l}\text { Sum of } \\
\text { ranks }\end{array}$ & $\begin{array}{l}\text { Mann- } \\
\text { Whitney } \\
\text { Utest }\end{array}$ & Significance \\
\hline \multirow[t]{2}{*}{ Identity diffusion } & Clinical & 14.45 & 144.50 & 10.500 & 0.003 \\
\hline & Control & 6.55 & 65.50 & & \\
\hline \multirow[t]{2}{*}{ Self-devaluation } & Clinical & 14.15 & 141.50 & 33.500 & 0.221 \\
\hline & Control & 6.85 & 68.50 & & \\
\hline \multirow[t]{2}{*}{ Body disapproval } & Clinical & 11.95 & 119.50 & 35.50 & 0.268 \\
\hline & Control & 9.05 & 90.50 & & \\
\hline \multirow[t]{2}{*}{ Sexual discomfort } & Clinical & 12.65 & 126.50 & 28.500 & 0.098 \\
\hline & Control & 8.35 & 83.50 & & \\
\hline \multirow[t]{2}{*}{ Peer insecurity } & Clinical & 15.50 & 155.00 & 25.000 & 0.000 \\
\hline & Control & 5.50 & 55.0 & & \\
\hline \multirow[t]{2}{*}{ Social insensitivity } & Clinical & 13.65 & 136.50 & 28.500 & 0.097 \\
\hline & Control & 7.35 & 73.50 & & \\
\hline \multirow[t]{2}{*}{ Family discord } & Clinical & 15.50 & 155.00 & 25.000 & 0.000 \\
\hline & Control & 5.50 & 55.00 & & \\
\hline \multirow[t]{2}{*}{ Childhood abuse } & Clinical & 14.25 & 142.50 & 12.500 & 0.004 \\
\hline & Control & 6.75 & 67.50 & & \\
\hline
\end{tabular}

The Mann-Whitney $U$ test showed that adolescents with borderline personality traits have significantly higher identity diffusion $(U=10.50$, $p=0.003)$, family discord $(U=25.50, p=0.000)$, and childhood abuse $(\mathrm{U}=12.50, p=0.004)$ 
Table 2 suggests that adolescents with borderline personality traits have high impulsivity and eating dysfunction. Impulsivity in emerging BPD is a core element manifested through erratic behavior in response to real or perceived frustrations and setbacks. This may make adolescents with BPD traits more susceptible to eating dysfunction and impulse control problems. ${ }^{32}$

According to Cloninger's model of personality, patients with emerging BPD traits have high scores on the temperament measures of novelty seeking and harm avoidance; consequently they may have an approach-avoidance conflict that makes them more prone to euphoria, anger, depression, and anxiety. ${ }^{33}$ These results are concordant with the results of the present study in Table 3, which show high levels of Novelty Seeking and Harm Avoidance for the clinical group.

Persistence refers to the amount of time devoted to activity and exertion of effort to continue the work. The results show low persistence in the clinical group. Adolescents with borderline personality traits tend to have affective instability and impulsivity as their core features, which may lead to low persistence. ${ }^{34}$

In Table 4 adolescents with emerging borderline personality traits tend to have a significant elevation in all cognitive errors. Research suggest that adolescents with borderline personality traits habitually attend to negative stimuli and endorse consistent negative beliefs about self and others, making negatively biased interpretations and evaluation of neutral stimuli. ${ }^{35}$ These findings support the results of the present study, where the clinical group has a significant elevation in all cognitive errors. Furthermore, the cognitive style of emerging borderline personality may be viewed as a direct result of the split architecture of their object representations. When relationships are threatened, their level of ego functions begins to slip. This leads to distorted thinking based on wishes and fantasies, leading to higher cognitive errors. ${ }^{36}$ Personalization, which is the highest among adolescents with BPD traits, may be attributed to hypersensitivity to others and their relationships.

Table 2: Comparison between clinical and control groups in terms of clinical syndrome scales

\begin{tabular}{llrrll}
\hline & \multicolumn{5}{c}{ Mann- } \\
Variables & Group & rank & \multicolumn{1}{c}{ ranks } & U Utest & Significance \\
\hline Eating & Clinical & 13.60 & 136.00 & 19.000 & $\mathbf{0 . 0 1 9}$ \\
dysfunctions & Control & 7.40 & 74.00 & & \\
Substance abuse & Clinical & 12.65 & 126.50 & 28.500 & 0.102 \\
proneness & Control & 8.35 & 83.50 & & \\
Delinquent & Clinical & 13.05 & 130.50 & 24.500 & 0.051 \\
predisposition & Control & 7.95 & 79.50 & & \\
Impulsive & Clinical & 15.45 & 154.50 & 0.500 & $\mathbf{0 . 0 0 0}$ \\
propensity & Control & 5.55 & 55.50 & & \\
Anxious feelings & Clinical & 11.80 & 118.00 & 37.000 & 0.321 \\
& Control & 9.20 & 92.00 & & \\
Depressive affect & Clinical & 15.50 & 155.00 & 2.000 & $\mathbf{0 . 0 0 1}$ \\
& Control & 5.50 & 55.00 & & \\
Suicidal tendency & Clinical & 15.20 & 152.00 & 3.000 & $\mathbf{0 . 0 0 1}$ \\
& Control & 5.80 & 58.00 & & \\
\hline
\end{tabular}

The Mann-Whitney $\mathrm{U}$ test showed that adolescents with borderline personality traits have significantly higher eating dysfunctions $(U=19.00$, $p=0.019)$, impulsive propensity $(U=0.500, p=0.000)$, depressive affect $(U=2.00, p=0.001)$, and suicidal tendency $(U=3.00, p=0.001)$
In Table 5, social support, problem-solving and cognitive restructuring and expressed emotions scores were higher in the control group, whereas problem avoidance and wishful thinking scores were higher in the clinical group. Problem-solving and cognitive structuring requires active coping and planning. However, emotional dysregulation is an important feature of emerging BPD, which leads to a deficit in healthy and adaptive coping. Borderline personality traits include fear of abandonment and the process of devaluation as core features. This leads to lower levels of coping strategies such as social support and expressed emotions in BPD adolescents.

In terms of correlation, catastrophizing is significantly negatively correlated with cognitive restructuring and expressed emotions. Cognitive distortions and cognitive coping tend to be interlinked.

Table 3: Comparison between clinical and control groups in terms of temperament and character

\begin{tabular}{|c|c|c|c|c|c|}
\hline Variables & Group & $\begin{array}{l}\text { Mean } \\
\text { rank }\end{array}$ & $\begin{array}{l}\text { Sum of } \\
\text { ranks }\end{array}$ & $\begin{array}{l}\text { Mann- } \\
\text { Whitney } \\
\text { Utest }\end{array}$ & Significance \\
\hline \multirow[t]{2}{*}{ Novelty seeking } & Clinical & 15.40 & 154.00 & 1.000 & 0.001 \\
\hline & Control & 5.60 & 56.00 & & \\
\hline \multirow[t]{2}{*}{ Harm avoidance } & Clinical & 15.50 & 155.00 & 1.000 & 0.001 \\
\hline & Control & 5.50 & 55.00 & & \\
\hline \multirow{2}{*}{$\begin{array}{l}\text { Reward } \\
\text { dependence }\end{array}$} & Clinical & 12.40 & 124.00 & 31.000 & 0.150 \\
\hline & Control & 8.60 & 86.00 & & \\
\hline \multirow[t]{2}{*}{ Persistence } & Clinical & 7.55 & 75.50 & 20.500 & 0.023 \\
\hline & Control & 13.45 & 134.50 & & \\
\hline \multirow[t]{2}{*}{ Self-directedness } & Clinical & 8.95 & 89.50 & 34.500 & 0.239 \\
\hline & Control & 12.05 & 120.50 & & \\
\hline \multirow[t]{2}{*}{ Cooperativeness } & Clinical & 9.00 & 90.00 & 35.000 & 0.251 \\
\hline & Control & 12.00 & 120.00 & & \\
\hline \multirow[t]{2}{*}{ Self-transcendence } & Clinical & 12.10 & 121.00 & 34.000 & 0.223 \\
\hline & Control & 8.90 & 89.00 & & \\
\hline
\end{tabular}

The Mann-Whitney $U$ test showed that adolescents with borderline personality traits have significantly higher novelty seeking $(U=1.000$, $p=0.001)$, harm avoidance $(U=1.000, p=0.001)$, and lower persistence $(\mathrm{U}=20.50, p=0.023)$

Table 4: Comparison between clinical and control groups in terms of cognitive errors

\begin{tabular}{|c|c|c|c|c|c|}
\hline Variables & Group & $\begin{array}{l}\text { Mean } \\
\text { rank }\end{array}$ & $\begin{array}{l}\text { Sum of } \\
\text { ranks }\end{array}$ & $\begin{array}{l}\text { Mann- } \\
\text { Whitney } \\
\text { Utest }\end{array}$ & Significance \\
\hline \multirow[t]{2}{*}{ Catastrophizing } & Clinical & 13.50 & 135.00 & 1.000 & 0.001 \\
\hline & Control & 5.50 & 55.00 & & \\
\hline \multirow[t]{2}{*}{ Overgeneralization } & Clinical & 12.50 & 125.00 & 2.000 & 0.001 \\
\hline & Control & 5.50 & 55.00 & & \\
\hline \multirow[t]{2}{*}{ Personalization } & Clinical & 15.20 & 152.00 & 3.000 & 0.002 \\
\hline & Control & 5.80 & 58.00 & & \\
\hline \multirow{2}{*}{$\begin{array}{l}\text { Selective } \\
\text { abstraction }\end{array}$} & Clinical & 13.45 & 134.50 & 1.000 & 0.001 \\
\hline & Control & 5.55 & 55.50 & & \\
\hline
\end{tabular}

A Mann-Whitney $\mathrm{U}$ test showed that adolescents with borderline personality traits have significantly higher catastrophizing $(U=1.000, p=0.001)$, overgeneralization $(U=2.000, p=0.001)$, personalization $(U=3.000$, $p=0.002)$, and selective abstraction $(U=1.000, p=0.001)$ 
Table 5: Comparison between clinical and control groups in terms of coping strategies

\begin{tabular}{|c|c|c|c|c|c|}
\hline Variables & Group & $\begin{array}{l}\text { Mean } \\
\text { rank }\end{array}$ & $\begin{array}{l}\text { Sum of } \\
\text { ranks }\end{array}$ & $\begin{array}{l}\text { Mann- } \\
\text { Whitney } \\
U \text { test }\end{array}$ & Significance \\
\hline \multirow[t]{2}{*}{ Problem-solving } & Clinical & 5.60 & 56.00 & 1.000 & 0.000 \\
\hline & Control & 15.40 & 154.00 & & \\
\hline \multirow{2}{*}{$\begin{array}{l}\text { Cognitive restruc- } \\
\text { turing }\end{array}$} & Clinical & 6.40 & 64.00 & 9.000 & 0.002 \\
\hline & Control & 14.60 & 146.00 & & \\
\hline \multirow{2}{*}{$\begin{array}{l}\text { Expressed emo- } \\
\text { tions }\end{array}$} & Clinical & 6.75 & 67.50 & 12.500 & 0.004 \\
\hline & Control & 14.25 & 142.50 & & \\
\hline \multirow[t]{2}{*}{ Social support } & Clinical & 5.70 & 57.00 & 2.000 & 0.000 \\
\hline & Control & 15.30 & 153.00 & & \\
\hline \multirow[t]{2}{*}{ Problem avoidance } & Clinical & 14.80 & 148.00 & 7.000 & 0.000 \\
\hline & Control & 6.20 & 62.00 & & \\
\hline \multirow[t]{2}{*}{ Wishful thinking } & Clinical & 15.35 & 153.50 & 1.500 & 0.000 \\
\hline & Control & 5.65 & 56.50 & & \\
\hline \multirow[t]{2}{*}{ Self-criticism } & Clinical & 15.50 & 155.00 & 31.500 & 0.298 \\
\hline & Control & 13.50 & 135.00 & & \\
\hline \multirow[t]{2}{*}{ Social withdrawal } & Clinical & 15.10 & 151.00 & 24.000 & 0.251 \\
\hline & Control & 12.90 & 129.0 & & \\
\hline
\end{tabular}

The Mann-Whitney $\mathrm{U}$ test showed that adolescents with borderline personality traits have significantly higher problem avoidance $(U=7.000, p=0.000)$ and wishful thinking $(U=1.500, p=0.000)$. However, adolescents with borderline personality traits have significantly lower problem-solving $(U=1.000$, $p=0.000)$, cognitive restructuring $(U=9.000, p=0.002)$, expressed emotion $(\mathrm{U}=12.50, p=0.004)$, and social support $(\mathrm{U}=2.000, p=0.000)$

According to the information-processing model, negative cognitive processing of stressful events activates the primal cognitive mode, which leads to maladaptive coping, whereas positive perception may enhance negative thinking patterns. Results indicate a significantly negative correlation between persistence and suicidal tendency. Persistence refers to perseverance despite frustration and fatigue. Thus, when individuals have low persistence, they are unable to cope with everyday challenges and stressors, leading to higher suicidal tendencies. ${ }^{37}$

There exists a significantly negative correlation between selfdirectedness and impulsivity. Self-directedness refers to the ability to regulate and adapt behavior to the demands of the situation to achieve personally chosen goals, whereas impulsivity refers to the failure to inhibit behavioral impulse and act on immediate instincts. Thus, there are two contrary behavioral approaches and thus may be negatively correlated.

There has been an elevation in novelty seeking and harm avoidance behavior. Both these psychological constructs are dynamically an opponent to each other, leading to the persistent approach-avoidance conflict in the client. This may in turn lead to increased emotional lability. Furthermore, the client has increased identify diffusion, family discord, and childhood abuse contributing to the presence of anxiety and depression. The study also explores the interaction between the different variables, which further gives insight into the topic. The present study further assists in determining the relationship between the cognitive errors and coping abilities and its role in emerging BPD to modify the deficits through therapeutic intervention.

The study findings have far-reaching implications in the management of borderline personality traits, thereby preventing its manifestation as an adult personality disorder. Cognitive behavior therapy (CBT) is primarily used for the early intervention of borderline personality traits. CBT aims to elicit cognitive errors, leading to the development of core symptom formation. Furthermore, therapy aims to strengthen the coping skills of adolescents while reinforcing positive personality traits. Thus, the study would facilitate recovery through accurate psychopathology formulation. The study also suggests the importance of family counseling and teaching positive parenting approaches for preventing BPD. Furthermore, therapy should aim to foster early confidence-building skills to combat issues of identity and insecurity. The study would also assist in developing effective behavioral and psychological therapeutic management plans for adolescents considering the factors contributing to its symptom along with comorbid associated pathology.

In terms of limitation, a rating scale was used in the study which automatically included the self-reporting biases along with the possibility of some faking. Furthermore, the unequal number of males and females in each group may lead to certain gender biasness. However, according to the Diagnostic and Statistical Manual of Mental Disorders, fourth edition, Text Revision (DSM IV $\mathrm{TR}){ }^{38}$ there is a 3:1 female-to-male gender ratio. This may have led to a greater proportion of female samples in the study.

\section{Conclusion}

In the current study, a significant difference has been observed between the clinical and control group in terms of expressed concerns, clinical syndromes, cognitive errors, and coping strategies. Adolescents with borderline traits tend to have high cognitive errors and maladaptive coping strategies along with comorbid temperamental and characterological traits. This study would be useful in gaining better insight into the psychopathologies contributing to the development of borderline personality organization in adolescents, thereby leading to earlier and effective therapeutic intervention, improving the treatment prognosis.

\section{References}

1. Cicchetti D, Crick NR. Precursors and diverse pathways to personality disorder in children and adolescents. Dev Psychopathol 2009;21(3):683-685. DOI: 10.1017/S0954579409000388.

2. Gunderson JG, Lyons-Ruth K. BPD's interpersonal hypersensitivity phenotype: a gene environment-developmental model. J Pers Disord 2008;22(1):22-41. DOI: 10.1521/pedi.2008.22.1.22.

3. Hughes AE, Crowell SE, Uyeji L, et al. A developmental neuroscience of borderline pathology: emotional dysregulation and social baseline theory. J Abnorm Child Psychol 2012;40(1):21-33. DOI: 10.1007/ s10802-011-9555-x.

4. Fonagy $\mathrm{P}$, Luyten $\mathrm{P}$, Allison $\mathrm{E}$, et al. What we have changed our minds about: borderline personality disorder as a limitation of resilience. Borderline Personal Disord Emot Dysregul 2017;11:4-11. DOI: 10.1186/ s40479-017-0061-9.

5. Winsper $C$. The aetiology of borderline personality disorder (BPD): contemporary theories and putative mechanisms. Curr Opin Psychol 2018;21:105-110. DOI: 10.1016/j.copsyc.2017.10.005.

6. Elliot RL, Campbell L, Hunter M, et al. When I look into my baby's eyes ... infant emotion recognition by mothers with borderline personality disorder. Infant Ment Health J 2014;35(1):21-32. DOI: 10.1002/imhj.21426.

7. Horvath $A O$. The therapeutic relationship: from transference to alliance. J Clin Psychol 2000;56(2):163-173.

8. Perry J, Drapeau M, Dunkley D. The coping action pattern rating scale manual. Montreal Canada: McGill University; 2005. 
9. Ozment JM, Lester D. Helplessness, locus of control and psychological health. J Soc Psychol 2001;141(Suppl 1):137-138. DOI: 10.1080/00224540109600535.

10. Folkman S, Lazarus R. An analysis of coping in middle-aged community sample. J Health Soc Behav 1980;21(3):219-239. DOI: $10.2307 / 2136617$.

11. Caspi A. The child is father of the man: Personality continuities from childhood to adulthood. J Pers Soc Psychol 2000;78(1):158-172. DOI: 10.1037/0022-3514.78.1.158.

12. Rothbart MK. Temperament, development and personality. Curr Dir Psychol Sci 2007;16(4):207-212.

13. Clark LA, Watson $D$. Temperament: an organizing paradigm for trait psychology. In: John OP, Robins RW, Pervin LA, editors. Handbook of Personality: Theory and Research, 3rd ed., New York NY: Guilford Press; 2008. pp. 265-286.

14. Cailhol L, Pelletier E, Rochette L. Prevalence, mortality and health care use among patients with cluster B personality disorders clinically diagnosed in Quebec: a provincial cohort study, 2001-2012. Can J Psychiatry 2017;62(5):336-342. DOI: 10.1177/0706743717700818.

15. Murthy RS. National mental health survey of India 2015-2016. Indian J Psychiatry 2017;59:21-26. DOI: 10.4103/psychiatry. IndianJPsychiatry_102_17.

16. Sadock BJ, Sadock VA, Ruiz P. Kaplan and Sadock's Comprehensive Textbook of Psychiatry, 10th ed., Philadelphia: Lippincott; Williams and Wilkins; 2017.

17. Chanen AM, Jackson HJ, Mcgorry PD, et al. Two years stability of personality disorder in older adolescent outpatients. J Pers Disord 2004;18(6):526-541. DOI: 10.1521/pedi.18.6.526.54798.

18. Sharp C, Green KL, Yaroslavasky I, et al. The incremental validity of borderline personality disorder relative to major depressive disorder for suicidal ideation and deliberate self harm in adolescents. J Pers Disord 2012;26(6):927-938. DOI: 10.1521/pedi.2012.26.6.927.

19. Knafo A, Guile JM, Breton JJ, et al. Coping strategies associated with suicidal behaviour in adolescent inpatients with borderline personality disorder. Can J Psychiatry 2015;60(2):S46-S54.

20. Greenfield B, Henry M, Lis E. Correlates, stability and predictors of borderline personality disorder among previously suicidal youth. Eur Child Adolesc Psychiatry 2015;24(4):397-406. DOI: 10.1007/s00787014-0589-9.

21. Millon T, Davis RD. The millon adolescent personality inventory and the millon adolescent clinical inventory. J Couns Dev 1993;71(5):570574. DOI: https://doi.org/10.1002/j.1556-6676.1993.tb02244.x.

22. Cloninger $\mathrm{CR}$. The temperament and character inventory: a guide to its development and use. St Louis, MO: Centre for Psychobiology of Personality, Washington University; 1994.

23. Lefebvre MF. Cognitive distortions and cognitive errors in depressed psychiatric and low back pain patients. J Consult Clin Psychol 1981;49(4):517-525. DOI: 10.1037//0022-006x.49.4.517.
24. Tobin DL, Reynolds R, Garkse J, et al. The influence of self efficacy expectations on coin efforts. Presented at the meeting of the Association for the Advancement of Behaviour Therapy, Philadelphia; 1984.

25. Kuppuswamy B. Manual of socio-economic status scale (urban). Delhi: Manasayan; 1981.

26. Kernberg O. Borderline personality organization. J Am Psychoanal Assoc. 1967;15(3):641-685. DOI: 10.1177/000306516701500309.

27. Bowlby J. The making and breaking of affectional bonds. $\mathrm{Br} J$ Psychiatry 1997;130:201-210.

28. Benjamin LS. Interpersonal diagnosis and treatment of personality disorders. New York: Guilford; 1993.

29. Bromfield L, Higgins D. Chronic child maltreatment in an Australian statutory child protection sample. National comparison of child protection systems 2005;22:102-106.

30. Widom CS, Czaja SJ, Paris JJ. A prospective investigation of borderline personality disorder in abused and neglected children followed up into adulthood. J Pers Disord 2009;23(5):433-446. DOI: 10.1521/ pedi.2009.23.5.433.

31. Paris J. Borderline personality disorder. CMAJ 2005;172(12):1579-1583. DOI: https://doi.org/10.1503/cmaj.045281.

32. Ball SA, Tennen H, Poling JC, et al. Personality, temperament, and character dimensions and the DSM-IV personality disorders in substance abusers. J Abnorm Psychol 1997;106(4):545-553. DOI: 10.1037//0021-843x.106.4.545.

33. Cloninger CR. Psychobiological model of temperament and character. Arch Gen Psychiatry 1993;50(12):975-990. DOI: 10.1001/ archpsyc.1993.01820240059008.

34. Stepp SD, Keenan K, Hipwell AE, et al. The impact of childhood temperament on the development of borderline personality disorder symptoms over the course of adolescence. Borderline Personal Disord Emot Dysregul 2014;1:18. DOI: 10.1186/20516673-1-18.

35. Baer RA, Peters JR, Eisenlohr-Moul TA, et al. Emotion-related cognitive processes in borderline personality disorder: a review of the empirical literature. Clin Psychol Rev 2012;32(5):359-369. DOI: 10.1016/j. cpr.2012.03.002.

36. Beck AT, Freeman AM. Cognitive therapy of personality disorders. New York: Guilford Press; 1990.

37. Hopwood CJ, Donnellan MB, Zanarini MC. Temperamental and acute symptoms of borderline personality disorder: associations with normal personality traits and dynamic relations over time. Psychol Med 2010;40(11):1871-1878. DOI: 10.1017/ S0033291709992108.

38. American Psychiatric Association. Diagnostic and Statistical Manual of Mental Disorders, 4th ed., Washington, DC: American Psychiatric Association; 2000. Text Revision. DOI: 10.1093/ acrefore/9780199975839.013.104. 